\title{
EEN METERSLANGE DOEK MET DE VESSANTARA JĀTAKA
}

In 2014 verwierf het Nationaal Museum van Wereldculturen met financiële steun van het Mondriaanfonds een unieke meterslange doek uit Thailand of Laos met de afbeelding van de Vessantara Jātaka, een van de vorige levensverhalen van de Boeddha. De doek is in zijn geheel te zien zijn op de tentoonstelling De Boeddha: van levensverhaal tot inspiratiebron, die op II februari in Museum Volkenkunde in Leiden opende. Dergelijke doeken worden nog niet zo lang verzameld. Slechts tien andere zijn wereldwijd in museumcollecties bekend.'

\section{Jataka's}

Het levensverhaal van de Boeddha omvat niet alleen het verhaal van Prins Siddhartha die Boeddha wordt, maar ook de verhalen over zijn vorige U levens, de Jataka's. Als de Boeddha, vlak voor zijn ontwaking, tot een steeds dieper bewustzijn komt, herinnert hij zich deze. Bij verschillende gelegenheden vertelt hij ze aan zijn leerlingen. Een van de meest uitgebreide verzamelingen is een Pāli tekst die 547 vorige levens van de Boeddha beschrijft. Deze tekst is vooral bekend in Sri Lanka en ZuidoostAzië. De eerste verhalen zijn kort en vaak is de Boeddha een dier, bijvoorbeeld een aap die een apenkolonie helpt vluchten, of een hert, dat een verdrinkende man redt. Maar hij is ook een brahmaan, een koopman, of een koning. Naarmate de tekst vordert, worden de verhalen langer. De laatste tien hebben een speciale plaats in het theravāda boeddhisme. De Bodhisattva - de naam voor de Boeddha als hij nog niet Boeddha is - brengt in deze verhalen zijn deugdzaamheid tot perfectie. Zo toont de Sāma Jātaka liefdevolle vriendelijkheid, de Mahosadha Jātaka wijsheid en de Vessantara Jātaka ultieme vrijgevigheid. ${ }^{2}$

\section{De Vessantara Jātaka}

De Vessantara Jātaka is het laatste, $547^{\mathrm{e}}$ geboorteverhaal in deze Pāli tekst. Het is een van de populairste verhalen van het theravāda boeddhisme. Het verhaal vertelt van de uitermate vrijgevige Prins Vessantara. Al vanaf zijn geboorte geeft hij alles weg. De climax van het verhaal is wanneer hij met pijn in het hart zijn kostbaarste bezit, zijn twee kinderen (een meisje en een jongen), aan een brahmaan geeft die ze vervolgens, als zijn slaafjes, 
slecht behandelt. Tenslotte geeft Vessantara ook zijn vrouw weg. Maar uiteindelijk krijgt ieder wat hij verdient: Vessantara wordt eerst met zijn vrouw en daarna met zijn kinderen herenigd en samen keren ze terug naar het paleis; de slechte brahmaan komt daarentegen door vraatzuchtig overeten aan zijn eind. Door zijn uitermate altruïstische vrijgevigheid vergroot Prins Vessantara zijn deugdzaamheid en religieuze verdienste zo, dat hij in zijn volgende, laatste leven Boeddha kan worden.

\section{De Vessantara doek (pha yao Phra Wet)}

Dit lange Jātaka-verhaal, 6o pagina's in de uitgave van E.B. Cowell, ${ }^{3}$ is in 45 scènes op deze katoenen doek afgebeeld. De doek is ongeveer 90 centimeter hoog en 36 meter lang. Het is een kleurrijke doek met een heldere tekening. Hij komt uit Noordoost-Thailand (Isan) of het aangrenzende deel van Laos. Volgens de Thai-Lao traditie bestaat het Vessantara verhaal uit 13 delen (kan). De namen van de verschillende kan zijn in dikke letters bovenaan de doek te vinden. In deze streek heeft vrijwel elke boeddhistische tempel (wat) zo'n doek, die jaarlijks tevoorschijn wordt gehaald voor het Bun Phra Wet feest, het grote ritueel ter vermeerdering van verdienste (bun), waarin Vessantara (Phra Wet) centraal staat. Helemaal links en rechts is mogelijk een stuk van de doek weg. Bij andere vergelijkbare doeken is daar een tekstgedeelte, dat documenteert wanneer en door wie de doek is gemaakt en wie financieel bijdroegen. Aan de bovenkant van de doek zijn hier en daar ook stukken weg, op punten waar de doek oorspronkelijk op stokken in processie werd gedragen of in de tempel werd opgehangen. De doek toont op verschillende plaatsen reparaties. Soms gaat het om delen die veel zijn aangeraakt, vanwege hun zegenende werking, zoals waarschijnlijk het vervaagde en ingescheurde deel waar Vessantara's twee belangrijkste geschenken, van zijn kinderen en zijn vrouw, zijn te zien (afb. 7).

\section{De scènes}

Hieronder volgt een korte beschrijving van de scènes op de doek, in de volgorde zoals ze op de doek zijn afgebeeld, maar genummerd in de volgorde van het verhaal (de doek geeft de scènes niet in de volgorde van

Afb. 1

Vessantara doek, compleet, katoen beschilderd, $3600 \mathrm{x}$ $90 \mathrm{~cm}$., NoordoostThailand (Isan) of het aangrenzende deel van Laos, ca. 1950-1960, Nationaal Museum van Wereldculturen, inv.nr. NMVW 7006-1 de tekst, maar gooit ze een beetje door elkaar. De lezer dient zelf heen en weer te springen om het verhaal te kunnen volgen):

I. God Indra geeft Phusati (de moeder van Vessantara) tien wensen.

2. Phusati geeft de net geboren Vessantara een geldbuidel, die hij onmiddellijk weggeeft.

5. Vessantara en zijn gezin nemen afscheid van koning Sanjaya en koningin Phusati.

4. Het volk wil dat Vessantara wordt verbannen. Voordat hij vertrekt, geeft hij een geschenk van 700 kostbaarheden. 


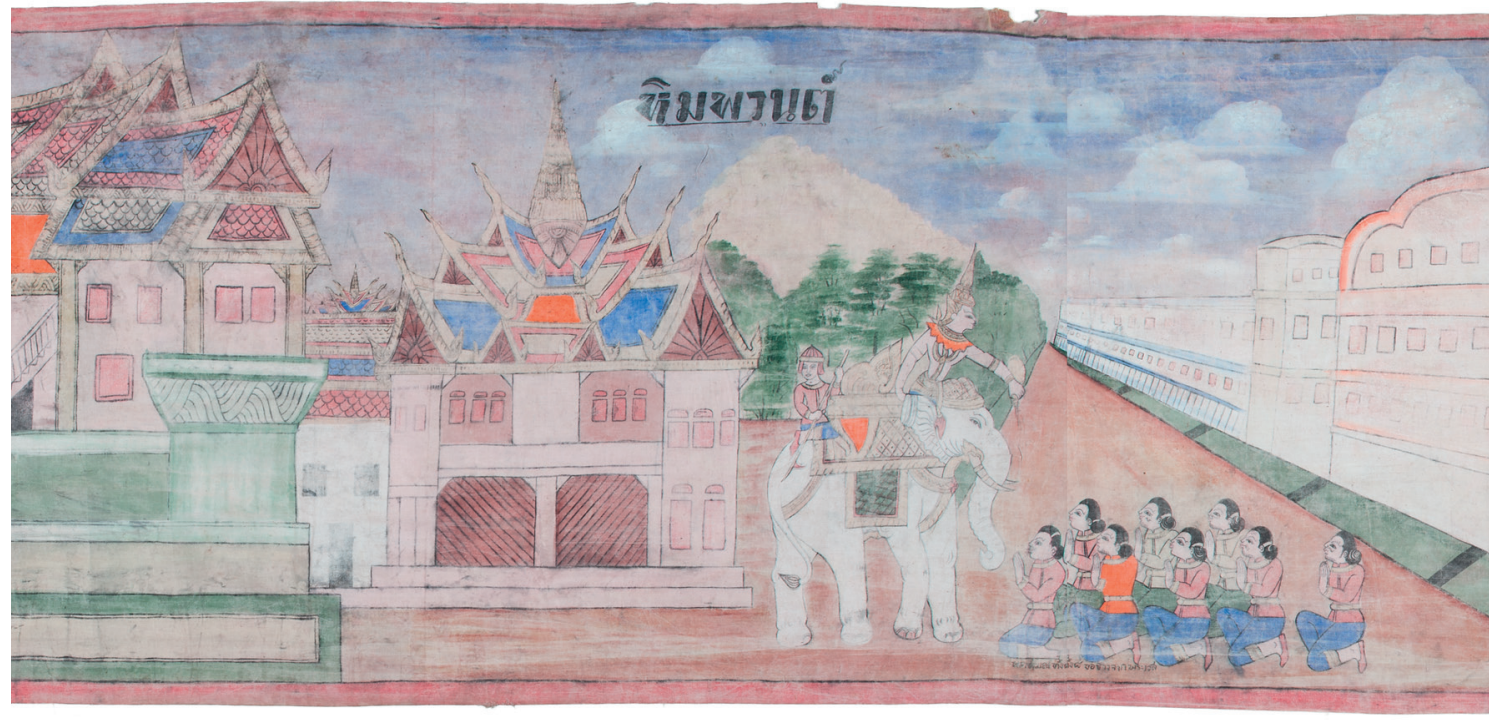

Afb. 2

Vessantara doek,

scène 3

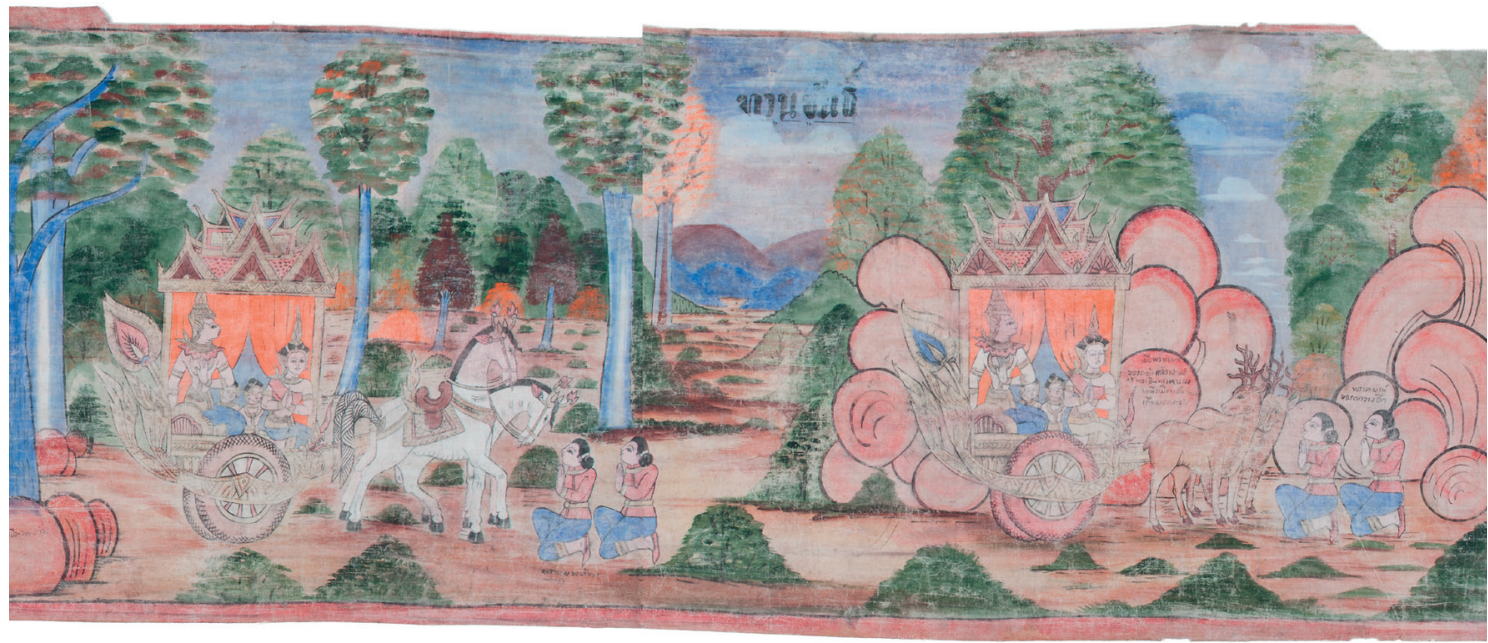

Afb. 3

Vessantara doek, scène 6 en 7

3. Vessantara geeft een witte olifant, die het koninkrijk geluk brengt, aan acht brahmanen (afb. 2).

6. Vessantara geeft de paarden van zijn wagen weg (afb. 3, links).

7. Voor de wagen staan nu herten (goden in vermomming); Vessantara geeft de wagen weg (afb. 3, rechts).

8. Vessantara en zijn vrouw Maddi gaan te voet verder, elk met een kind op de arm (afb. 4, links).

9. Onderweg verblijven ze in Ceta bij Vessantara's oom (afb. 4, midden).

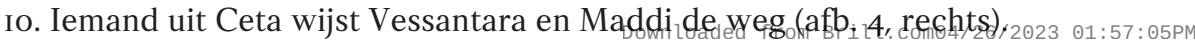


II. Een tweede verhaallijn begint nu. De oude brahmaan Jujaka krijgt de jonge vrouw Amittatapana, als haar vader zijn schuld aan hem niet kan aflossen (afb. 5, links).

I2. Jujaka neemt haar mee naar zijn huis (afb. 5, links van het midden). I4. Amittatapana wordt, als ze water haalt, door de andere vrouwen gepest om haar oude, lelijke man (afb. 5, rechts van het midden). I3. Amittatapana zorgt goed voor Jujaka in hun huisje op palen (afb. 5, rechts boven).

15. Jujaka stelt voor zelf water te halen, maar Amittatapana ziet dat als een schande (afb. 5, onder).

I6. Zij zet Jujaka onder druk om naar Vessantara te gaan (afb. 5, helemaal rechts) en hem zijn kinderen te vragen, zodat die water kunnen halen. I7. Amittatapana zwaait Jujaka uit.

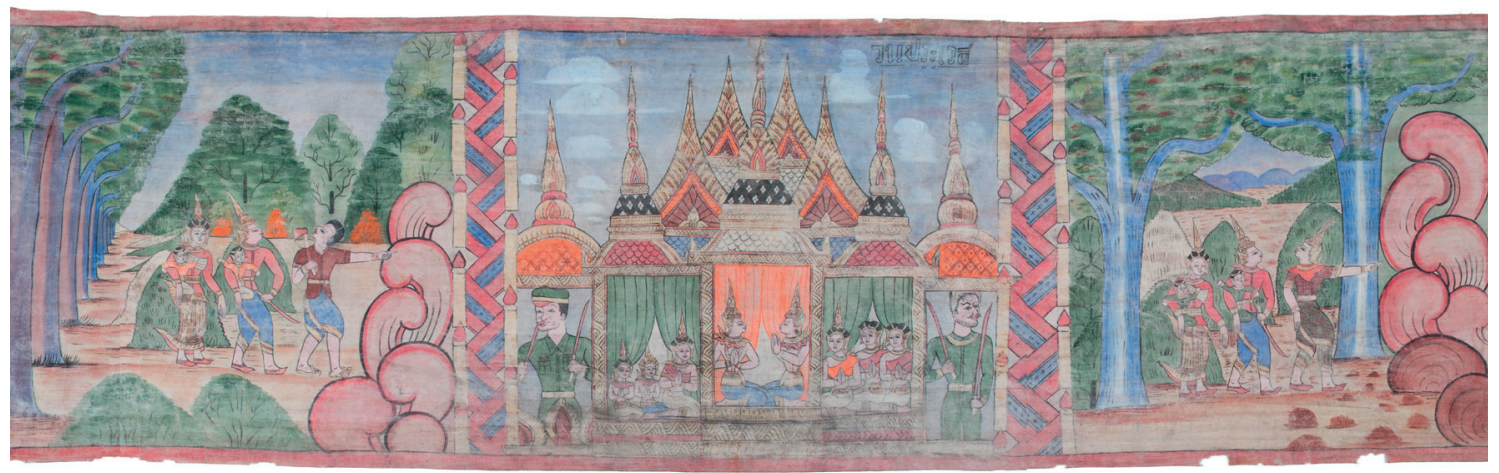

Afb. 4

Vessantara doek,

scène $8 \mathrm{t} / \mathrm{m} 10$

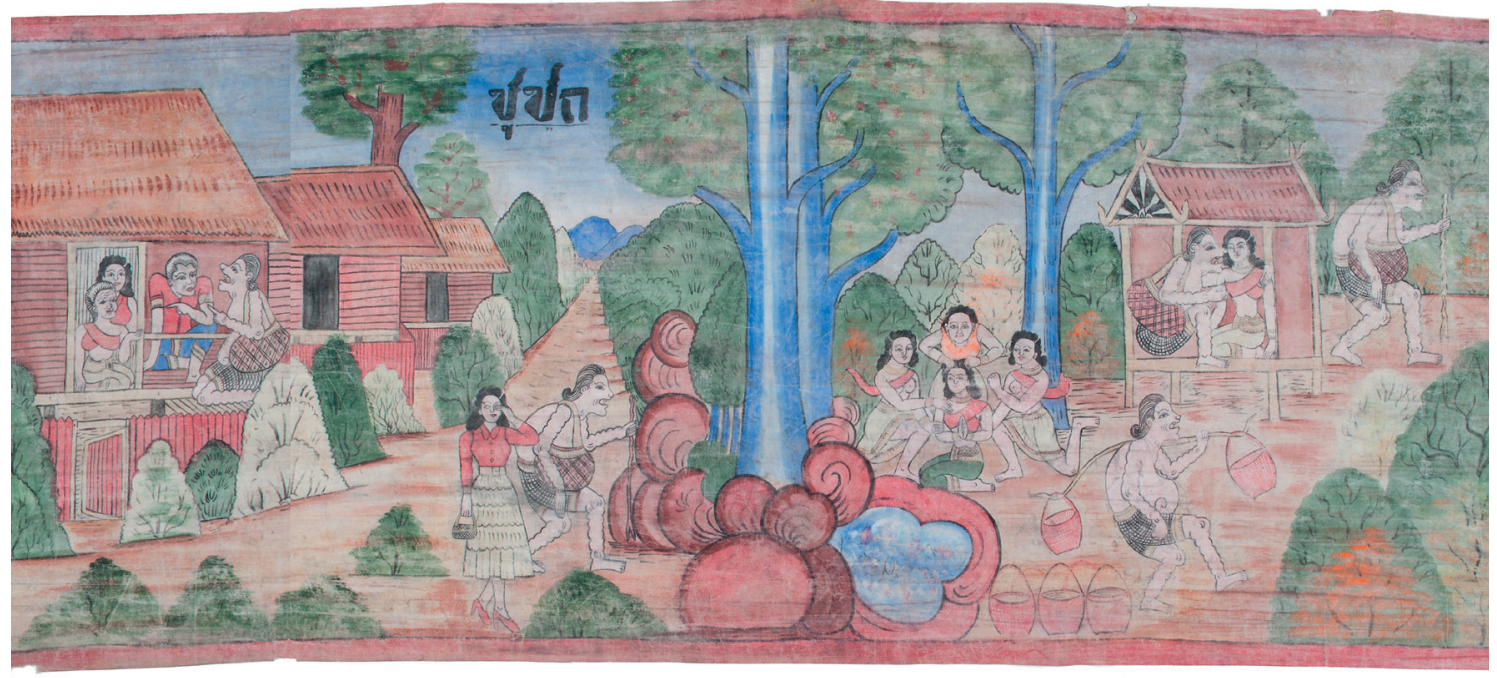

Afb. 5 


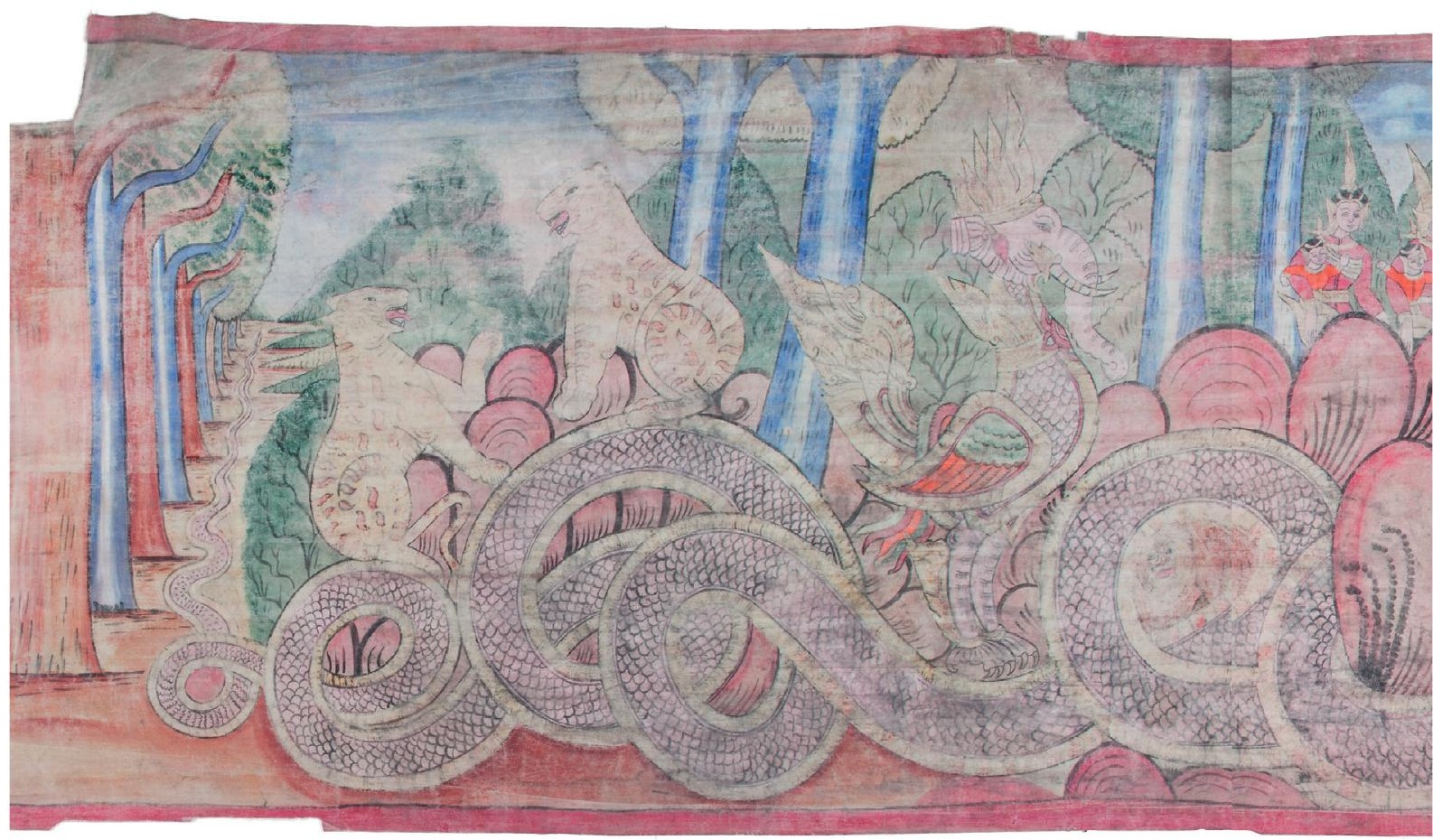

Afb. 6

Vessantara doek,

scène 24 


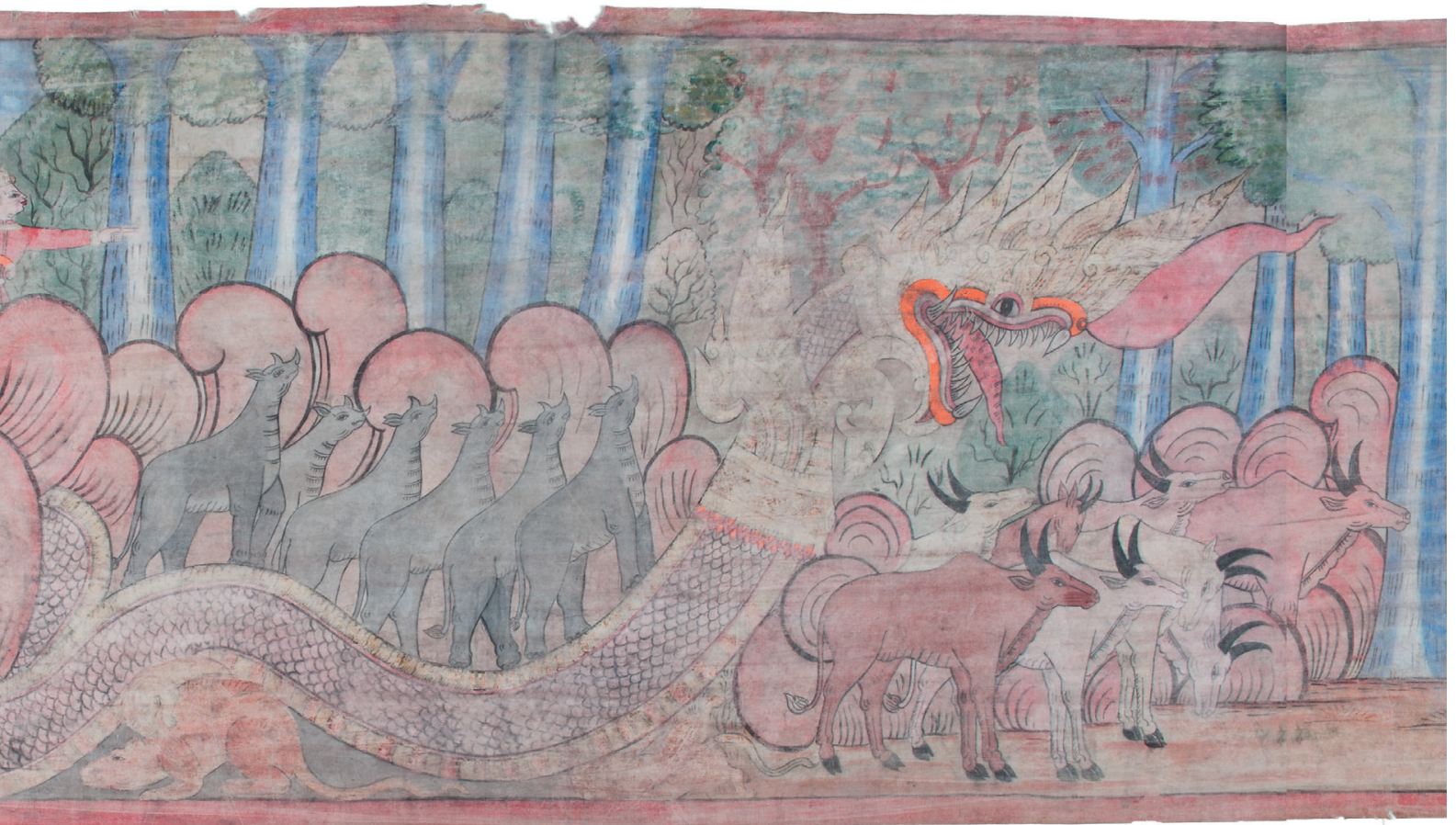

I8. Een bosopziener is met zijn honden in het bos.

I9. Jujaka ontmoet de bosopziener, die hem eerst wil doden, omdat hij hem eerst niet vertrouwt.

20. Jujaka wint zijn vertrouwen en de bosopziener wijst hem de weg.

2I. Jujaka vervolgt zijn weg.

22. Jujaka ontmoet de asceet Accata, die hem eerst niet vertrouwt maar dan toch de weg wijst.

23. Jujaka vervolgt zijn weg.

24. Vessantara en Maddi lopen met de kinderen op hun arm door het bos, dat vol zit met wonderlijke beesten (afb. 6). Ze gaan naar de kluizenarij, waar ze vervolgens zullen verblijven.

25. Jujaka komt aan bij de kluizenarij van Vessantara.

26. Jujaka slaapt op een heuvel en vraagt de volgende dag om de kinderen.

Maddi is er dan niet. 


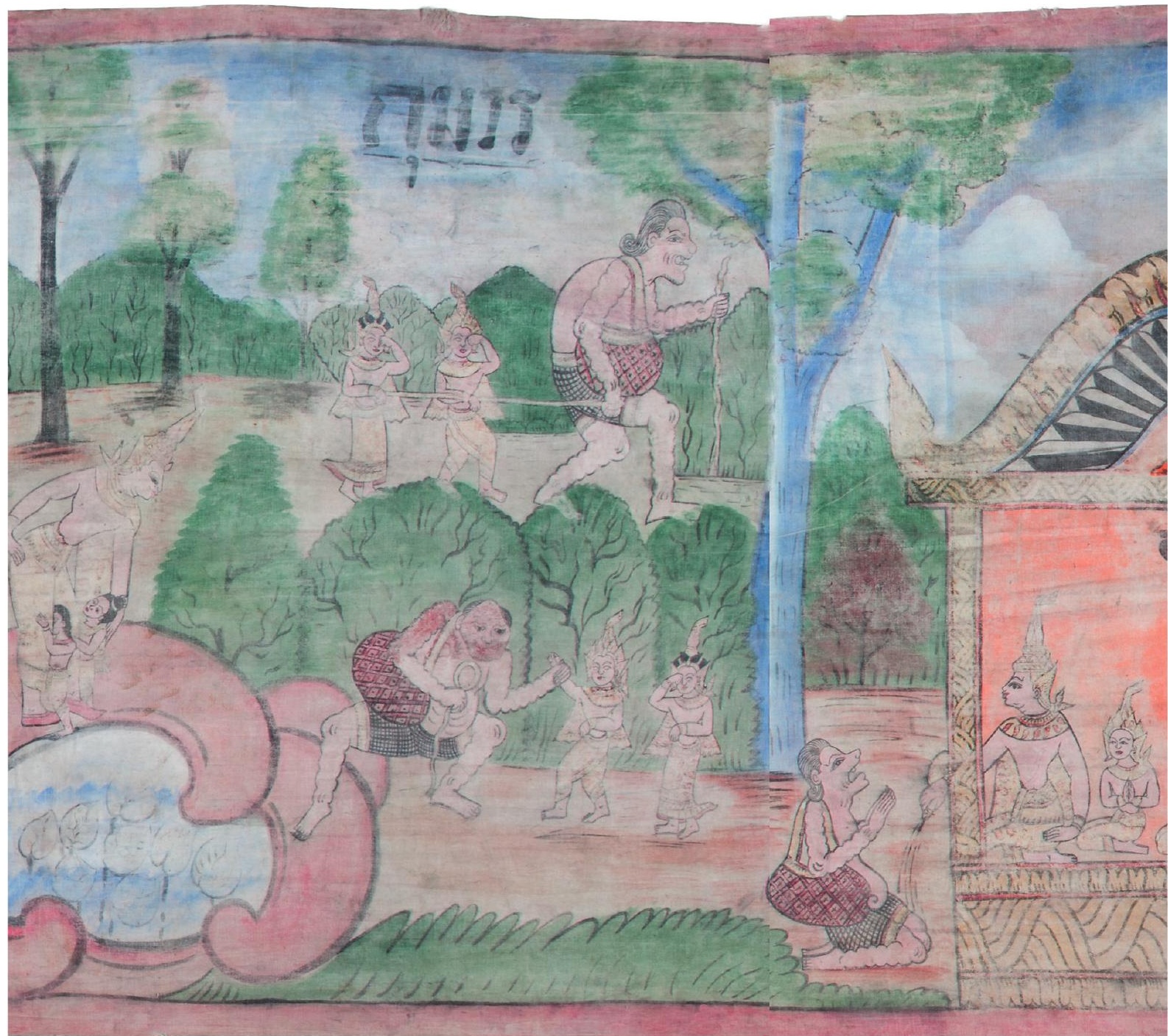

Afb. 7

Vessantara doek,

scène $27 \mathrm{t} / \mathrm{m}$ 30, 38

en 39 


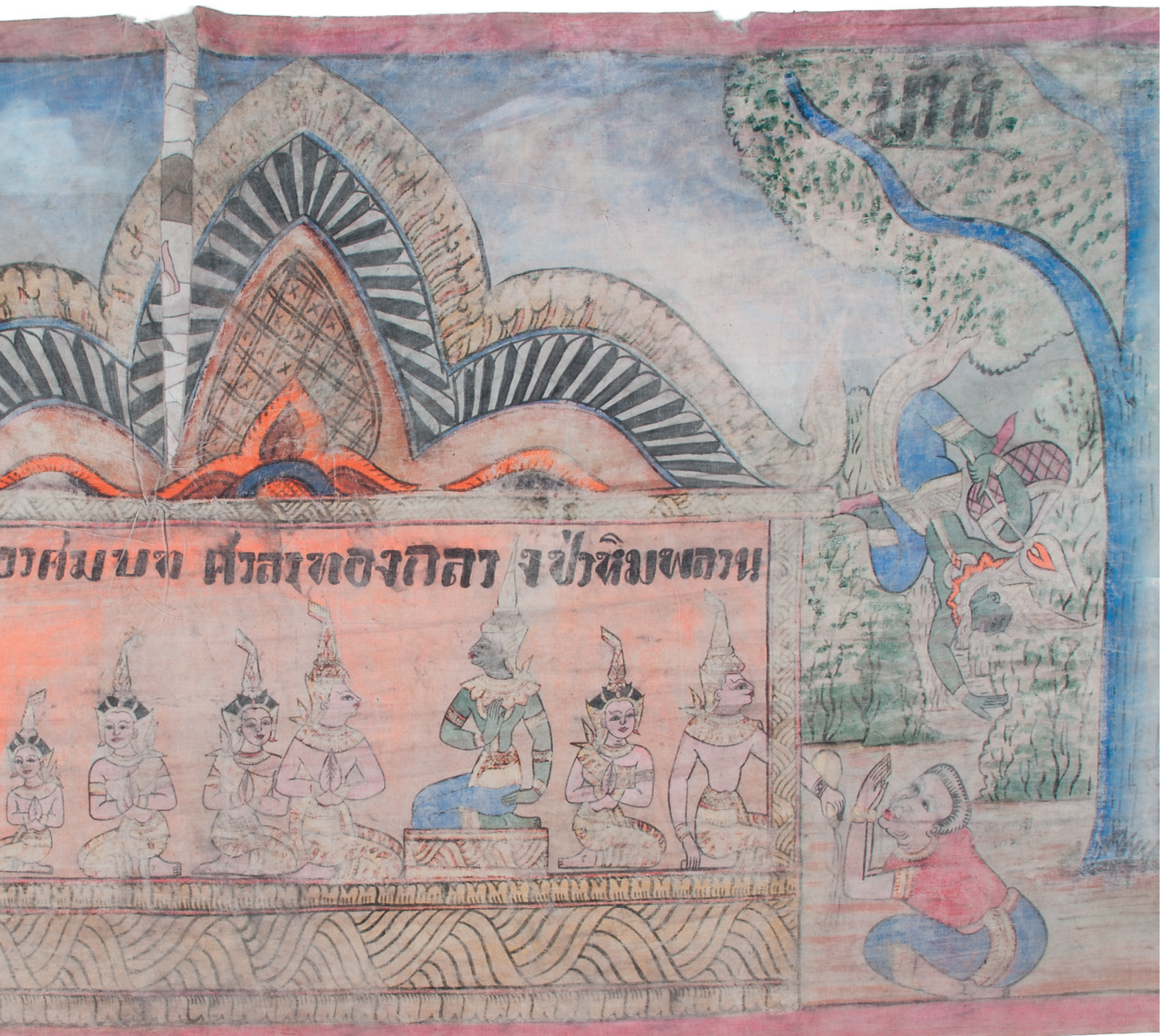

27. Vessantara laat zijn kinderen uit de vijver komen, waar zij zich hebben verstopt (afb. 7 , links).

30. Jujaka trekt de vastgebonden kinderen mee (afb. 7, links boven). 29. Jujaka wil de kinderen vastbinden (afb. 7 , links).

28. Vessantara geeft zijn kinderen aan Jujaka (afb. 7, gebouw, links). 39. God Indra geeft Maddi weer terug aan Vessantara (afb. 7, gebouw, midden).

38. Vessantara geeft Maddi aan de god Indra die de gedaante van een brahmaan heeft aangenomen (afb. 7, gebouw, rechts). 


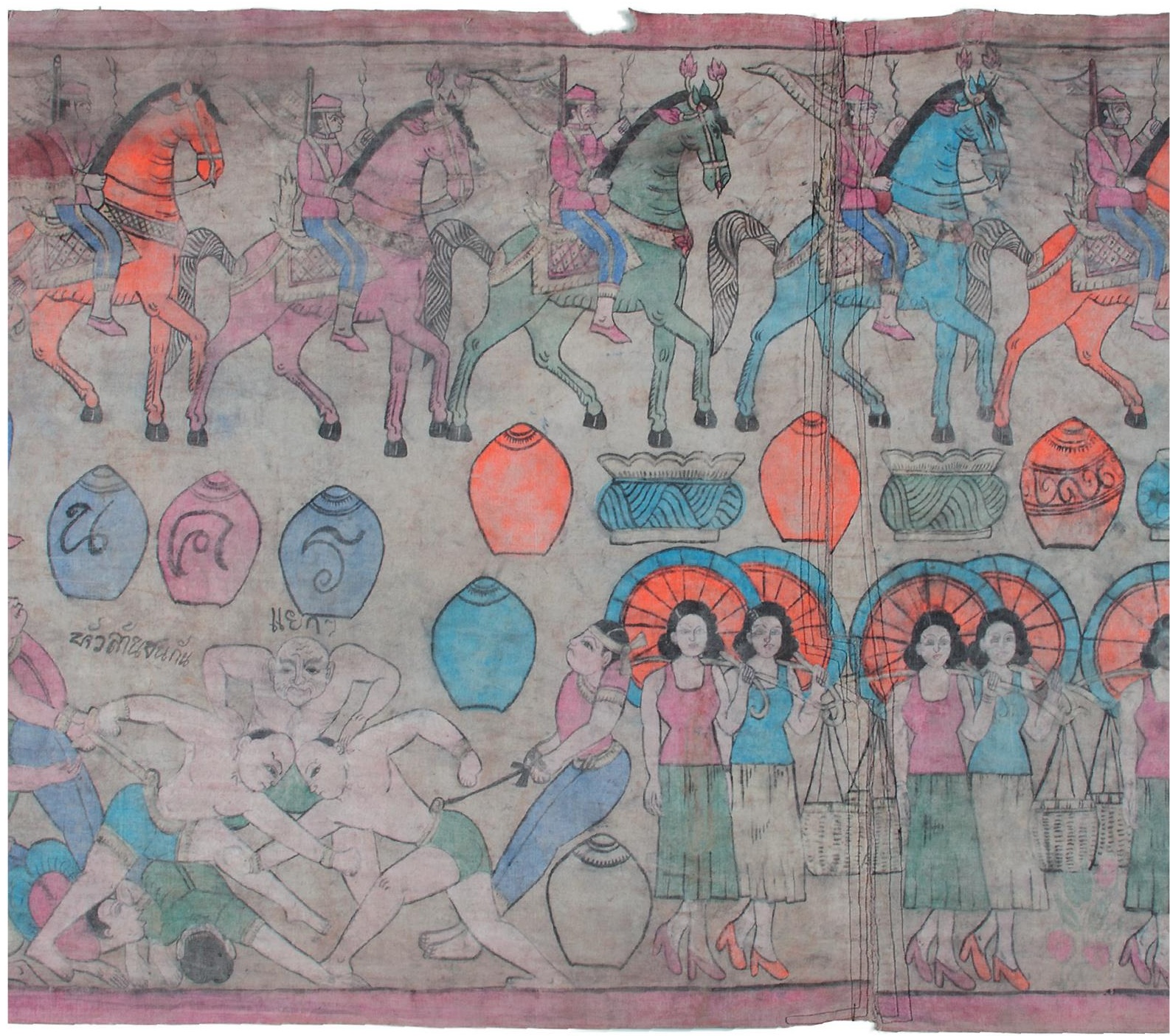

Afb. 8

Vessantara doek, deel

van scène 45

34: Maddi komt terug uit het bos en merkt dat de kinderen er niet zijn.

35: Maddi gaat haar zoontje en dochtertje zoeken.

36: Maddi gaat de kinderen nog een keer zoeken.

37: Maddi gaat voor de derde keer de kinderen zoeken.

33. Maddi wordt tegengehouden door wilde dieren (eigenlijk goden in vermomming), zodat zij Vessantara's geschenk niet zal dwarsbomen.

3I. Maddi zoekt ondertussen vruchten in het bos.

32. Maddi zoekt knollen in het bos.

40. Jujaka en de kinderen zijn op weg naar Jujakad's huis, Brill.come4/26/2023 01:57:05PM 


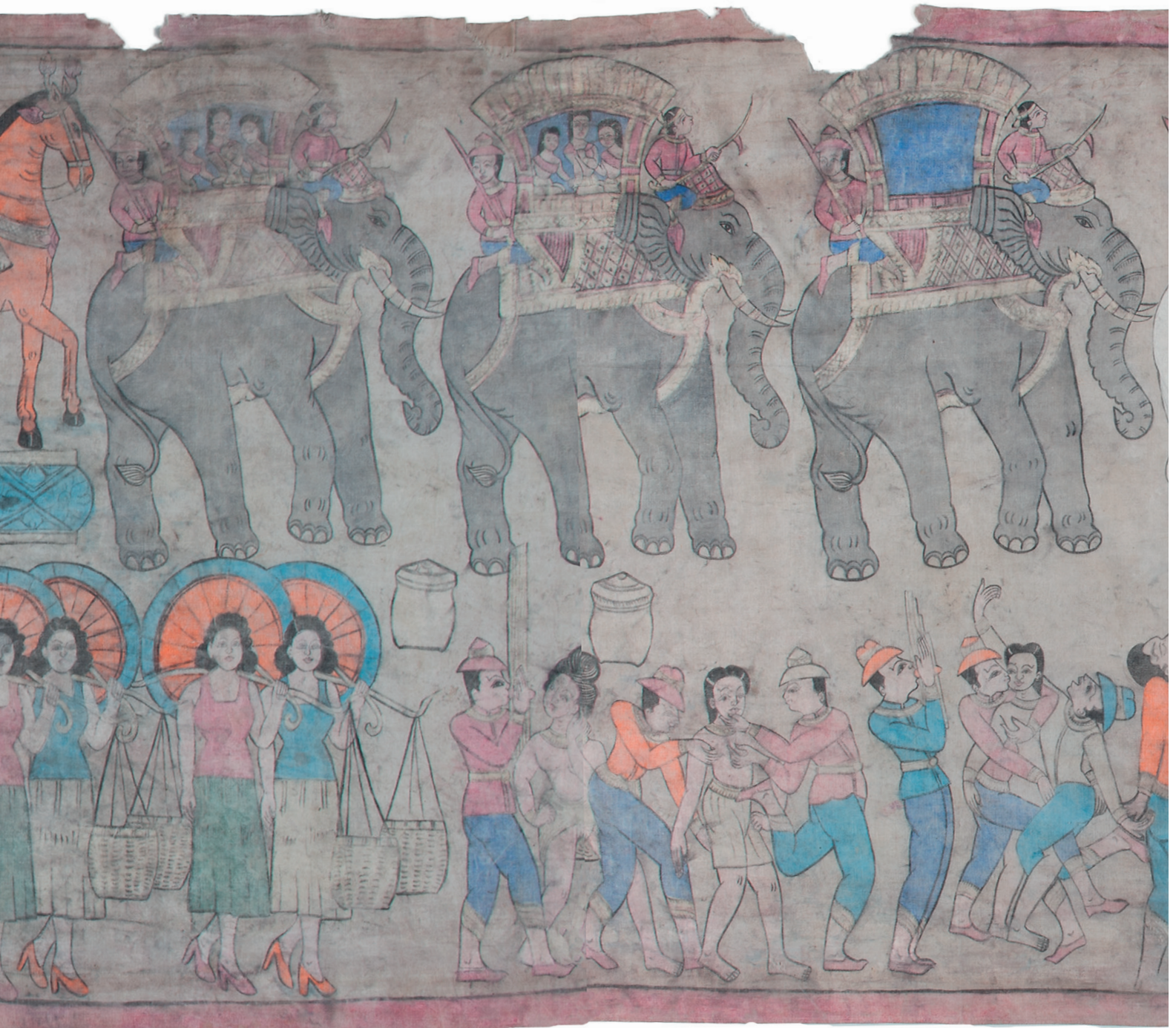

4I. Onderweg komen ze bij het paleis van Sanjaya en Phusati, de vader en moeder van Vessantara.

42. Deze herkennen hun kleinkinderen en kopen ze los. Jujaka krijgt veel lekkers te eten.

43. Jujaka eet zo veel dat hij sterft.

44. Sanjaya en Phusati gaan met hun kleinkinderen naar de kluizenarij om

Vessantara en Maddi terug te halen.

45. De processie terug naar het koninkrijk (afb. 8). 


\section{Datering}

Dergelijke doeken worden nog steeds gemaakt. Vanwege hun vergankelijke materiaal dateren de meeste doeken niet van voor het eind van de ${ }^{\mathrm{e}}{ }^{\mathrm{e}}$ eeuw. ${ }^{4}$ Soms worden ze lang hersteld, voordat er weer een nieuwe doek wordt gemaakt. Dat proces van herstellen zien we ook op deze doek. Interessant is dat deze doek vrouwen in westerse kleding laat zien. Ze dragen een rok tot op de kuiten, een mouwloos shirtje, hakschoenen en/of een handtasje (afb. 5 en 8). Dit zou er op kunnen wijzen dat de doek rond de tijd van de Tweede Wereldoorlog werd gemaakt. De Thaise bevolking werd toen namelijk verplicht gesteld om westerse kleding te dragen. Leedom Lefferts, kenner op het gebied van deze doeken, denkt echter dat de doek van wat later datum is, tussen 1950 en I960, omdat dit soort doek schaars was in de Tweede Wereldoorlog. Ook constateerde hij dat gebruik is gemaakt van sjablonen. ${ }^{5}$ Het zou kunnen zijn dat die wel uit iets eerdere tijd stammen. Een stilistisch vergelijkbare doek, die van zelfde sjablonen gebruik lijkt te hebben gemaakt, is gedateerd in $1955 .^{6}$

\section{Rituele context}

Tijdens het Bun Phra Wet ritueel wordt het leven van Vessantara door de hele gemeenschap gevierd en opnieuw geleefd. Op de eerste dag van het ritueel wordt de Vessantara doek uit de tempel gehaald en wordt Vessantara verwelkomd. Dan wordt het verhaal door de gemeenschap nagespeeld. De deelnemers vormen Vessantara's onderdanen die hem in het bos buiten het dorp opzoeken en vragen terug te keren naar het paleis. Met de hele koninklijke familie uit het verhaal herenigd, keren ze dan terug naar de dorpstempel, terwijl ze de meterslange Vessantara doek dragen. De doek wordt daar opgesteld. Op de tweede dag wordt het Vessantara verhaal door monniken in de tempel gereciteerd. Wie financieel of anderszins bijdraagt aan het ritueel of erin participeert, vergroot zijn religieuze verdienste. Het verhoogt de kans om geboren te worden in een utopische tijd waarin er weer een nieuwe Boeddha zal zijn. De leer direct van een Boeddha zelf horen, zal de weg naar nirvana versnellen. De doek wordt dus niet gebruikt om het verhaal van de ene scène naar de andere te vertellen. Iedereen kent het verhaal, dat een diepe emotie oproept en verlangen naar die utopische tijd. In de doek huist de geest van Vessantara.7 Zijn terugkeer in het dorp, dat tijdelijk het centrum van het koninkrijk is geworden, draagt de belofte van deze utopische tijd in zich.

- Marijke Klokke is bijzonder hoogleraar Kunst en materiële cultuur van Zuid- en Zuidoost-Azië aan de Universiteit Leiden en conservator Klassiek Zuid- en Zuidoost-Azië bij Museum Volkenkunde Leiden/ Tropenmuseum Amsterdam.

- DE BOEDDHA: van levensverhaal tot inspiratiebron

Museum Volkenkunde Leiden, I2 februari t/m I4 augustus 2016 
Naomi Appleton, Sarah Shaw en Toshiya Unebe, Illuminating the life of the Buddha: an illustrated chanting book from eighteenth-century Siam, Oxford, 2013.

E.B. Cowell (ed.), The Jātaka, or stories of the Buddha's former births, part VI, Pali Text Society ; London, 1973. [Translated from the Pāli by various hands under the editorship of E. B. Cowell.]

Leedom Lefferts en Sandra Cate, Buddhist storytelling in Thailand and Laos: the Vessantara Jataka scroll at the Asian Civilisations Museum, Singapore, 2012.

Leedom Lefferts en Sandra Cate, 'Constructing multiple narratives in Theravada Buddhism: the Vessantara painted scrolls of Northeast Thailand and Lowland Laos', in: Alexandra Green (ed.), Rethinking visual narratives from Asia, pp. 22943, Hong Kong, 2013.

\section{NOTEN}

* Fotografie: Irene de Groot. Stichting Nationaal Museum van Wereldculturen.

I Moesgaard Museum Denemarken, British Museum Londen, Walters Art Museum Baltimore, Asian Art Museum San Francisco, Phoenix Art Museum, Asian Civilisations Museum Singapore, Ubon Ratchathani National Museum, Anthropology Museum Nakhon Ratchasima.

2 Appleton, Shaw en Unebe 2013: 12.

3 Cowell 1973 The Pali Text Society (http://www.sacred-texts.com/bud/j6/j6or3. htm).

4 Lefferts en Cate 2012, 2013.

5 E-mail correspondentie, 4-5 september 2014.

6 Lefferts en Cate 2013: 235, fig.13.5; 240-24I, fig.I3.IO.

7 Lefferts en Cate 2013: 236. 


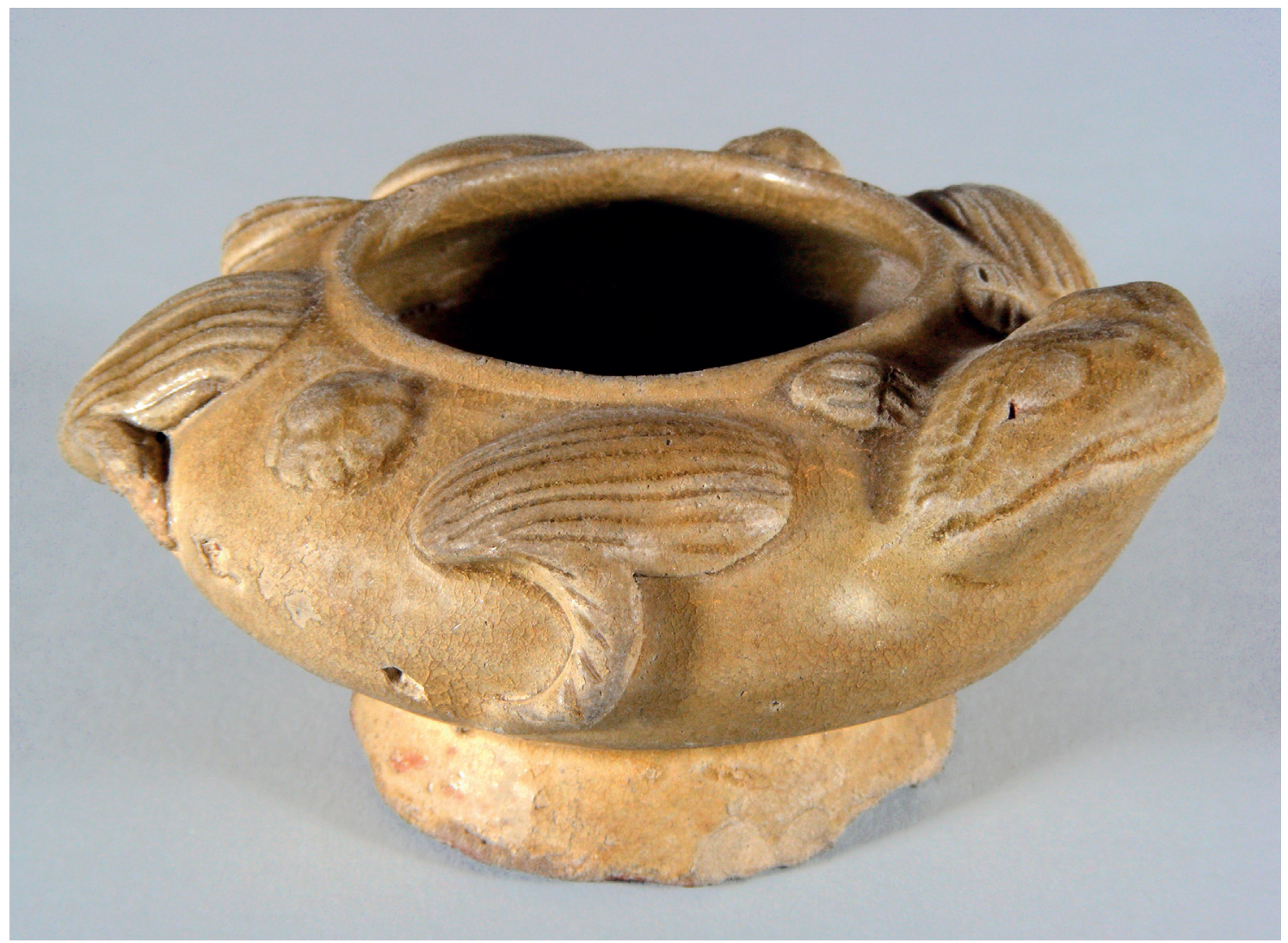

Fig. 1

Water dropper in

the shape of a frog,

Yue stoneware, 4.6

$x 7.6 \mathrm{~cm}$., Southern

China, Western Jin

(265-317), Museum het

Princessehof, OKS

1958-7. On loan from

the Ottema-Kingma

Stichting 